\title{
Development of Score Based Smart Risk Prediction Tool for Detection of Type-1 Diabetes: A Bioinformatics and Machine Learning Approach
}

\author{
Fuyad Al Masud 1,2 (D), Md. Sazib Hosen ${ }^{3}$ (i), Arzo Ahmed 4 (i), Mamun Ibn Bashar ${ }^{4}$ (i), Abdul \\ Muyeed 5 (D), Sohely Jahan 6 (D), Bikash Kumar Paul 1,2,7 (D), Kawsar Ahmed 2,7,* (D) \\ 1 Department of Software Engineering, Daffodil International University, Sukrabad, Dhanmondi, Dhaka 1205, Bangladesh \\ 2 Department of Information and Communication Technology, Mawlana Bhashani Science and Technology University \\ (MBSTU), Santosh, Tangail, 1902, Bangladesh \\ 3 Jatio Mohila Sangstha, Ministry of Women and Children Affairs, Dhaka-1000, Bangladesh \\ 4 Department of Statistics, Mawlana Bhashani Science and Technology University Santosh, Tangail, 1902, Bangladesh \\ 5 Department of Statistics, Jatiya Kabi Kazi Nazrul Islam University, Trishal-2220, Mymensingh, Bangladesh \\ 6 Department of Computer Science and Engineering, University of Barisal, Barishal 8200, Bangladesh \\ 7 Group of Bio-photomatix, Mawlana Bhashani Science and Technology University (MBSTU), Santosh, Tangail 1902, \\ Bangladesh \\ * Correspondence: kawsar.ict@mbstu.ac.bd; k.ahmed.bd@ieee.org; kawsarit08050@gmail.com;
}

Scopus Author ID 34879354400

Received: 20.07.2020; Revised: 23.08.2020; Accepted: 26.08.2020; Published: 30.08.2020

\begin{abstract}
In this study, a smart risk prediction tool has been demonstrated along with the algorithm, which works as a backend of the tool to detect Type-1 Diabetes. The algorithm was contrived by the weightage values that are articulated by analyzing the risk factors of Type- 1 diabetes. The analysis takes place with a machine learning and statistical approach. Data were collected from a number of cases and control groups, which was preprocessed to be fit for the analysis. Risk factors were extracted by comparing two different approaches one is machine learning, and another is the statistical approach. A common regulatory pattern was found that leads to the design of an algorithm that gives a predictive result of the risk level of any user for Type-1 Diabetes. Elaborated results of different approaches have also been shown in this paper, which gives clear excogitation about risk factors and their ranking.
\end{abstract}

Keywords: Risk Factors; Type-1 Diabetes; Risk prediction tool; Data mining; Machine learning.

(C) 2020 by the authors. This article is an open-access article distributed under the terms and conditions of the Creative Commons Attribution (CC BY) license (https://creativecommons.org/licenses/by/4.0/).

\section{Introduction}

In recent years, there are several diseases that are pernicious for human life. Among those diseases, diabetes is mostly found. The abnormality of the exuberant level of sugar in the human blood assuredly produces very well-known diseases diabetes. It is a chronic condition and is directly associated with blood sugar levels. According to medical science and advanced research in this specific arena, diabetes is mainly classified into two major groups, one is type1 , and another is type-2. Type-1 diabetes is one of the major causes of death in worldwide people.Type-1 diabetes is not only a disease but also a cause of occurring different kinds of diseases like eye problems, thyroid problems, liver problems, heartbeat problems, Thalassemia, skin problem, and affect to heart problems with respect to Bangladesh. Recently dataset based research on Type-1 diabetes has been implemented [1]. Type-1 Diabetes is especially can happen for lower age groups like children [2]. Different factors like obesity, growth rate, education, age, hypoglycemic cause Type-1 Diabetes $[3,4,5]$. Type-1 diabetes is in every year, 
increasing at a rate of approximately 3\% (2013 year) per year in different countries around the world [6]. Type- 1 diabetes means insulin deficiency due to pancreatic $\beta$ cell damage [7]. Insulin means move sugar or glucose in the full body. When a person failed to make insulin in his body, then he is affected by type- 1 diabetes. People are affected in type- 1 diabetes in 30 million in 1985 to 150 million in 2000 and then to 246 million in 2007, according to the International Diabetes Federation. It expects this number to hit 380 million by 2025 [8]. They are more than many child are suffering from type- 1 diabetes. Nowadays, many people are hesitant about their future life. As a result, the child can not continue his/her study properly. Day by day, many children are lost his/her good health. Type-1 diabetes also affects to foot or leg Disruption, and risk of infections, heart diseases in the human body. Type-1 diabetes patients are generally affected before age 25 years, and autoantibodies are present in $85-90 \%$ of individuals when fasting hyperglycemia is initially detected [9]. 20 years of age, 5-8\% of the offspring of diabetic men, and only $2-5 \%$ of the offspring of diabetic women have been found to be affected [11]. Generally realized to increase young children are at-risk, especially females are more risk in type-1 diabetes [10]. Approximately $90 \%$ of cases are sporadic, occurring in individuals, and no family history of type-1 diabetes in Japan [12]. The island of Sardinia has the secondhighest incidence of type- 1 diabetes in the world $(45 / 100,000)$, right after Finland $(64.2 / 100,000)$ [13]. Type-1 diabetes is affected by worldwide people. Like as, Madeira Island was 7.2/100,000 per year, Portiere was 21.1/100,000 per year, New Zealand was 21.9/100,000 per year, Auckland was 12.3/100,000 per year, China was 0.1/100,000 per year [14]. The risk of type 1 diabetes in the offspring of diabetic fathers is high than in the offspring of diabetic mothers [15]. In addition, a lot of works are presented on diabetes in recent times $[16,17,18]$.

In this paper, a detailed analysis of risk factors of Type-1 Diabetes has been done and shown. The results show that 13 risk factors are highly significant and associated with Type-1 Diabetes. An algorithm and App was developed to detect the risk level of Type-1 Diabetes of any random person.

\section{Materials and Methods}

\subsection{Data collection and preprocessing.}

Data collection is a crucial factor in any survey-based research. In this research, data were collected by a questionnaire. The questionnaire was designed by the study of numerous research papers [1-7] related to Type-1 Diabetes and by discussing with medical persons. To collect data, the required sample size has been determined using the sample size determination process [20]. Data of 306 persons were collected from different diagnostic and medical centers at Dhaka in Bangladesh. Among them, 152 was the case, and the rest 154 was a control group of both male and female persons. Type-1 Diabetes occurs at an early age, so at the time of data collection, it was accounted for early age groups (details in Figure 1).

In a survey-based study, raw data may be inappropriate, inconsistent, missing, etc. So data preprocessing is much needed before analysis. In this research, a brute force approach is used to make inconsistent data consistent and missing values to proper values. Data preprocessing was also done by WEKA, a data mining tool that resets and retrieves the missing values. Targeted parameters and other parameters are organized for analysis. "Affected by Type-1 Diabetes" was the targeted value for the research. 


\subsection{Analysis.}

The whole analysis was done by using two data mining tools (Orange and WEKA) and a Statistical tool (SPSS). In recent years this type of risk prediction analysis has been done by both data mining [19,20] and the Statistical approach [21-23]. The main intention was to examine the risk factors by comparing it with two different approaches. In this research, data were collected for 22 different variables where few variables were numeric values. K-Means clustering algorithm was used by WEKA to make the category of the numerical factors (BMI, Age, Height, Weight, HBA1c).

Probability can be defined as the likelihood of an event that can happen from different events [8].

$$
\mathrm{P}(\mathrm{H} / \mathrm{D})=\frac{P(D / H) P(H)}{P(D)} .
$$

Where $\mathrm{P}(\mathrm{D} / \mathrm{H})$ is the likelihood function, and it causes the probability of the observed data from the hypothesis. $\mathrm{P}(\mathrm{H})$ is prior knowledge before learning about $\mathrm{D}, \mathrm{P}(\mathrm{H} / \mathrm{D})$ is the posterior probability of $\mathrm{H}$ after learning about $\mathrm{D}$ and $\mathrm{P}(\mathrm{D})$ obtained by integrating, which is sometimes called normalizing constant.

Chi-square $\left(\chi^{2}\right)$ Test is another important test to measure whether the factor is significantly associated or not.

$$
\chi^{2}=\sum \frac{(\text { Observed Value }- \text { Expected Value })^{2}}{\text { Expected Value }}
$$

A low value of chi-square means there is a high association between two sets of data. If observed and expected values were equal (no difference), then the chi-square value would be zero, which is rare in practical life. A high chi-square value indicates there is little or no association between two variables.

In the hypothesis test, the p-value is used to check the significance of results. Hypothesis tests can be used to test the validity of the claim that is called the null hypothesis. For ( $\mathrm{p} \leq 0.05)$, these null hypotheses can be omitted, whereas for ( $\mathrm{p} \geq 0.05)$, the null hypothesis cannot be omitted.

Ranker Algorithm has been used to find the significance level of risk factors. Significant factors are extracted from 22 factors using comparative analysis. Ranker algorithm gives ranking with a weightage value of significant factors.

\subsubsection{Algorithm design and tool implementation.}

A comparative analysis takes place on both data mining (WEKA) and statistical (SPSS) approaches. Among 22 factors highly significant and correlated, 13 risk factors are chosen. PValue and Chi-square tests are used to find the highly associated factors and level of significance among them.

Ranker algorithm analysis and probability analysis are also used to detect the significance among the significant factors. By comparing all the analysis, a final table (Table 3) has been implemented along with corresponding weightage values. By these weightage values, an algorithm has been designed that shows the probability of Low/Middle/High risk of Type 1 Diabetes. The minimum sum of weightage values is 33 , and the highest weightage value is 63. So, the difference is $63-33=30$. Interval is $30 / n=30 / 3=10$ (Here $n=3$ as total three risk level). By designing an algorithm, an android based App was developed, which can be used to detect the risk level of any person. 


\section{Results and Discussion}

All the factors and subfactors are evaluated in such a way. Figure 2 shows the distribution of different age groups. The figure illustrates the correlation between age group and affected three dimensions of height, weight, and BMI.

Table 1. P-value and $\chi 2$ - Test of different factors.

\begin{tabular}{|c|c|c|c|c|}
\hline \multirow[t]{2}{*}{ Factors } & \multirow[t]{2}{*}{ P-value } & \multicolumn{2}{|c|}{$95 \%$ C. I for Odds ratio } & \multirow[t]{2}{*}{$\chi^{2}$ - Test } \\
\hline & & Lower & Upper & \\
\hline $\begin{array}{l}\text { Age } \\
\text { Less than } 5 \\
\text { Less than } 11 \\
\text { Less than } 15 \\
\text { Greater than } 15 \\
\end{array}$ & $0.000 *$ & 0.2633 & 0.4884 & 92.146 \\
\hline $\begin{array}{l}\text { Sex } \\
\text { Male } \\
\text { Female }\end{array}$ & $0.000 *$ & 0.1111 & 0.2235 & 11.843 \\
\hline $\begin{array}{l}\text { Area of Residence } \\
\text { Rural } \\
\text { Urban } \\
\text { Suburban }\end{array}$ & $0.000 *$ & 0.1489 & 0.3162 & 45.003 \\
\hline Height & 0.665 & 0.245 & 0.0384 & -------- \\
\hline Weight & 0.996 & 1.88 & 0.1 .89 & ----------- \\
\hline BMI & 0.996 & 0.70 & 0.70 & ---------- \\
\hline $\begin{array}{l}\text { Adequate Nutrition } \\
\text { Yes } \\
\text { No } \\
\end{array}$ & 0.008 & 0.0173 & 0.1163 & 16.361 \\
\hline $\begin{array}{l}\text { Education of Mother } \\
\text { Yes } \\
\text { No } \\
\end{array}$ & 0.999 & 0.0544 & 0.0544 & 18.491 \\
\hline $\begin{array}{l}\text { Standardized growth-rate infancy } \\
\text { Lowest quartile } \\
\text { Middle quartile } \\
\text { Highest quartile }\end{array}$ & 0.999 & 0.251 & 0.251 & 2.741 \\
\hline $\begin{array}{l}\text { Family History in Type-1 Diabetes } \\
\text { Father } \\
\text { Mother } \\
\text { Father's Heredity } \\
\text { Mother's Heredity }\end{array}$ & $0.000 *$ & 0.4522 & 0.5550 & 9.081 \\
\hline $\begin{array}{l}\text { Family History in Type-2 Diabetes } \\
\text { Father } \\
\text { Mother } \\
\text { Father's Heredity } \\
\text { Mother's Heredity }\end{array}$ & $0.000 *$ & 0.1864 & 0.2986 & 4.434 \\
\hline
\end{tabular}

The probability of different factors with their sub-factors along with ranking from the ranker algorithm has been shown in Table 2. The factors are placed according to their significance level. The higher value has the probability of the higher the risk [24]. Table 1 and Table 2 are used to find the significance values, and finally, Table 3 was demonstrated. Table 3 illustrates the weightage value of the factors and subfactors. The weightage values are given based on the analysis result from both Table 1 and Table 2. Ranking of the factors and their values, Probability, and its values, $\mathrm{p}$ values were considered to give the weightage values of the significant factors. Among 22 factors, 13 factors were identified as significant by the Statistical and Data mining approach. 


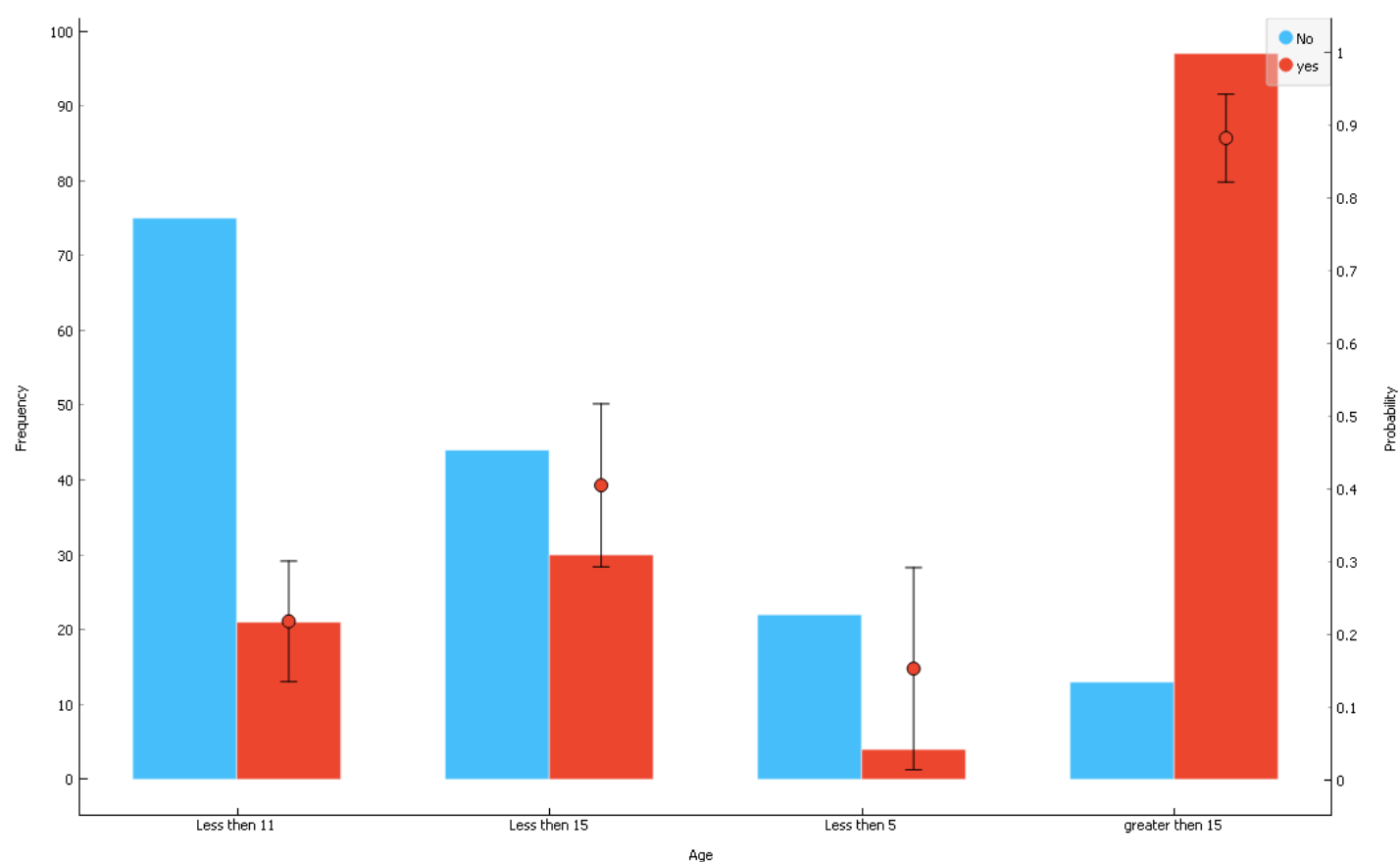

Figure 1. Frequency distribution along with probability with respect to different age groups.

Table 2. Probability Distribution and Significance ranking of different factors and sub-factors.

\begin{tabular}{|c|c|c|c|c|}
\hline No & Factors & Sub-factors & Probabilities & Ranking \\
\hline \multirow[t]{4}{*}{1} & \multirow{4}{*}{ Age } & Greater than 15 & 0.88 & \multirow{4}{*}{4} \\
\hline & & Less than 15 & 0.42 & \\
\hline & & Less than 11 & 0.2 & \\
\hline & & Less than 5 & 0.18 & \\
\hline \multirow[t]{2}{*}{2} & \multirow{2}{*}{ HBA1c } & Less than 7.5 & 0.21 & \multirow{2}{*}{2} \\
\hline & & Greater than 7.5 & 0.72 & \\
\hline \multirow[t]{2}{*}{3} & \multirow[t]{2}{*}{ Hypoglycemis } & Yes & 0.69 & \multirow{2}{*}{2} \\
\hline & & $\mathrm{No}$ & 0.27 & \\
\hline \multirow[t]{2}{*}{4} & \multirow{2}{*}{$\begin{array}{l}\text { Pancreatic Diseases diagnosed } \\
\text { in affected childs }\end{array}$} & Yes & 0.5 & \\
\hline & & No & 0.31 & \\
\hline \multirow[t]{3}{*}{5} & \multirow[t]{3}{*}{ Area of Residence } & Rural & 0.82 & \multirow{3}{*}{3} \\
\hline & & Suburban & 0.65 & \\
\hline & & Urban & 0.22 & \\
\hline \multirow[t]{2}{*}{6} & \multirow[t]{2}{*}{ Adequate Nutrition } & $\mathrm{No}$ & 0.86 & \multirow[t]{2}{*}{2} \\
\hline & & Yes & 0.36 & \\
\hline \multirow[t]{2}{*}{7} & \multirow[t]{2}{*}{ Autoantibodies } & No & 0.4 & \multirow{2}{*}{2} \\
\hline & & Yes & 0.38 & \\
\hline \multirow[t]{2}{*}{8} & \multirow[t]{2}{*}{ Sex } & Female & 0.65 & \multirow{2}{*}{2} \\
\hline & & Male & 0.36 & \\
\hline \multirow[t]{2}{*}{9} & \multirow[t]{2}{*}{ Family History type 1 Diabetes } & Yes & 0.68 & \multirow{2}{*}{2} \\
\hline & & No & 0.41 & \\
\hline \multirow[t]{2}{*}{10} & \multirow[t]{2}{*}{ Family History type 2 Diabetes } & Yes & 0.59 & \multirow[b]{2}{*}{2} \\
\hline & & No & 0.44 & \\
\hline \multirow[t]{3}{*}{11} & \multirow[t]{3}{*}{ Standard Growth Rate } & Lowest & 0.96 & \multirow{3}{*}{3} \\
\hline & & Height & 0.72 & \\
\hline & & Middle & 0.45 & \\
\hline
\end{tabular}

A smartphone-based risk prediction tool was developed by research on Heart Attack risks prediction [25], appendicitis Patients risk prediction [26]. In our research, a smart risk prediction tool is also designed for predicting the risk of Type-1 Diabetes. Figure 3 and Figure 4 shows the results of the research. Figure 3 shows the flowchart of the designed algorithm. The flowchart was designed by the weightage values of Table 3 . From Figure 3 , it can be illustrated that by giving a choice among the Factors of Table 3, all the sum of weightage values implies the risk level low or middle or high risk. Figure 4 shows the Implemented Apps using the flow chart of Figure 3. By using the App, one can easily detect the risk level of his/her Type-1 Diabetes. 


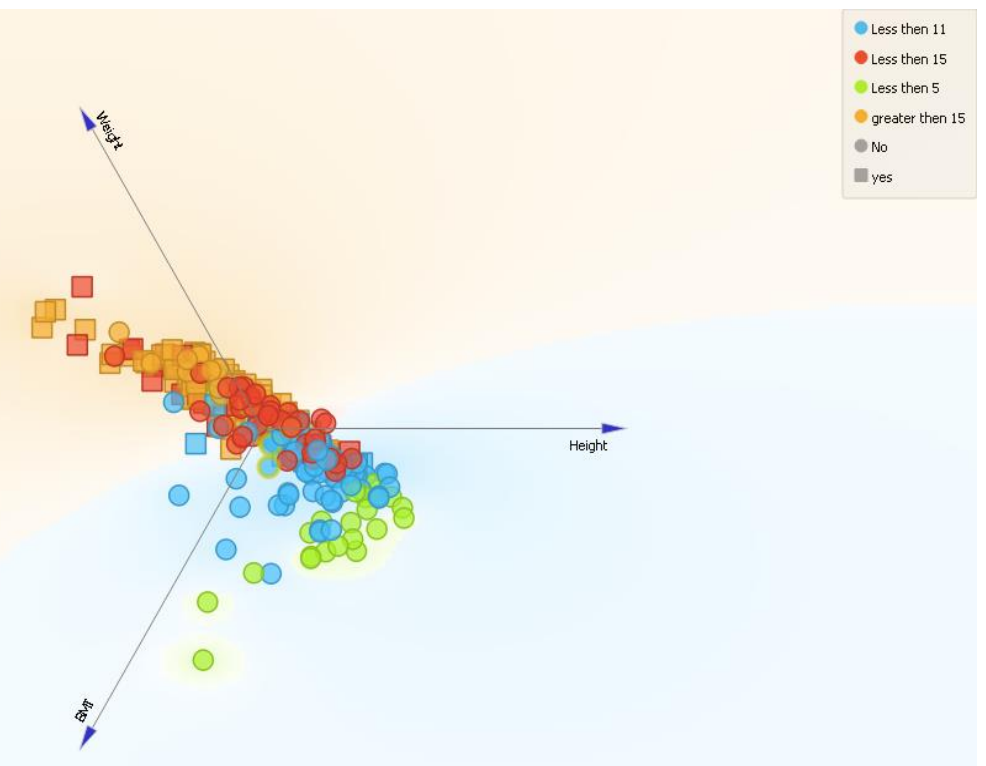

Figure 2. Affected and Non-affected density distribution of different age groups.

Table 3. Weightage value of different factors and sub-factors.

\begin{tabular}{|c|c|c|c|c|}
\hline No & Factors & \multicolumn{2}{|c|}{ Sub-factors } & Weightage value \\
\hline \multirow{4}{*}{1} & \multirow{4}{*}{ Age } & \multicolumn{2}{|c|}{ Greater than 15} & 8 \\
\hline & & \multicolumn{2}{|c|}{ Less than 15} & 6 \\
\hline & & \multicolumn{2}{|c|}{ Less than 11} & 5 \\
\hline & & \multicolumn{2}{|c|}{ Less than 5} & 4 \\
\hline \multirow[t]{3}{*}{2} & \multirow{3}{*}{ Standard Growth Rate } & \multicolumn{2}{|c|}{ Lowest } & 6 \\
\hline & & \multicolumn{2}{|c|}{ Height } & 5 \\
\hline & & \multicolumn{2}{|c|}{ Middle } & 3 \\
\hline \multirow[t]{3}{*}{3} & \multirow[t]{3}{*}{ Area of Residence } & \multicolumn{2}{|c|}{ Rural } & 6 \\
\hline & & \multicolumn{2}{|c|}{ Suburban } & 5 \\
\hline & & \multicolumn{2}{|c|}{ Urban } & 3 \\
\hline \multirow[t]{2}{*}{4} & \multirow[t]{2}{*}{ HBA1c } & \multicolumn{2}{|c|}{ Less than 7.5} & 2 \\
\hline & & \multicolumn{2}{|c|}{ Greater than 7.5} & 4 \\
\hline \multirow[t]{2}{*}{5} & \multirow{2}{*}{ Hypoglycemis } & \multicolumn{2}{|c|}{ Yes } & 6 \\
\hline & & \multicolumn{2}{|l|}{ No } & 4 \\
\hline \multirow[t]{2}{*}{6} & \multirow{2}{*}{$\begin{array}{l}\text { Pancreatic Diseases diagnosed in affected } \\
\text { childs }\end{array}$} & Yes & & 6 \\
\hline & & No & & 4 \\
\hline 7 & Adequate Nutrition & Yes & & 2 \\
\hline & & No & & 4 \\
\hline 8 & Autoantibodies & Yes & & 3 \\
\hline & & No & & 4 \\
\hline 9 & Sex & Fem & & 4 \\
\hline & & Male & & 2 \\
\hline 10 & Family History type 1 Diabetes & Yes & Mother & 4 \\
\hline & & & Father's Heredity & 3 \\
\hline & & & Mother's Heredity & 2 \\
\hline & & & Father & 1 \\
\hline & & No & & 1 \\
\hline 11 & Family History type 2 Diabetes & Yes & Mother & 4 \\
\hline & & & Father's Heredity & 3 \\
\hline & & & Father & 2 \\
\hline & & & Mother's Heredity & 1 \\
\hline & & No & & 1 \\
\hline 12 & Education of Mother & Yes & & 2 \\
\hline & & No & & 1 \\
\hline & Symptoms & Freq & nt Urination & 5 \\
\hline & & Incre & ed thirst & 4.5 \\
\hline 13 & & Fatig & and Weakness & 4 \\
\hline & & Unin & aded weight loss & 3.5 \\
\hline & & Extr & e Hunger & 3 \\
\hline
\end{tabular}




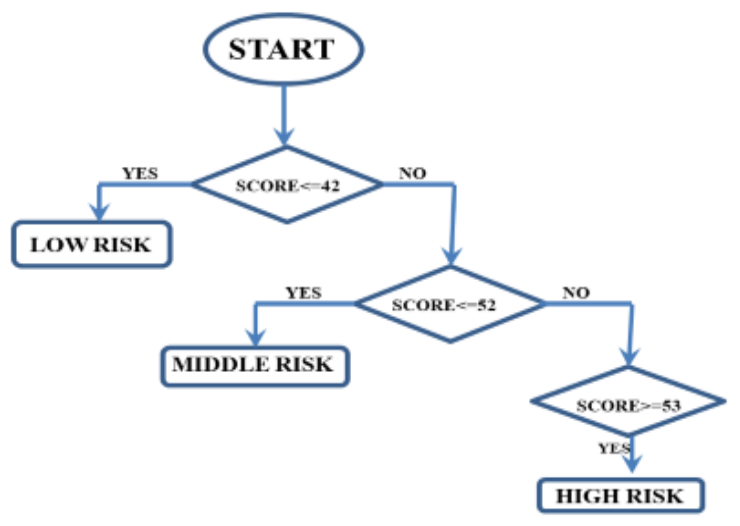

Figure 3. Flow chart of risk prediction algorithm.
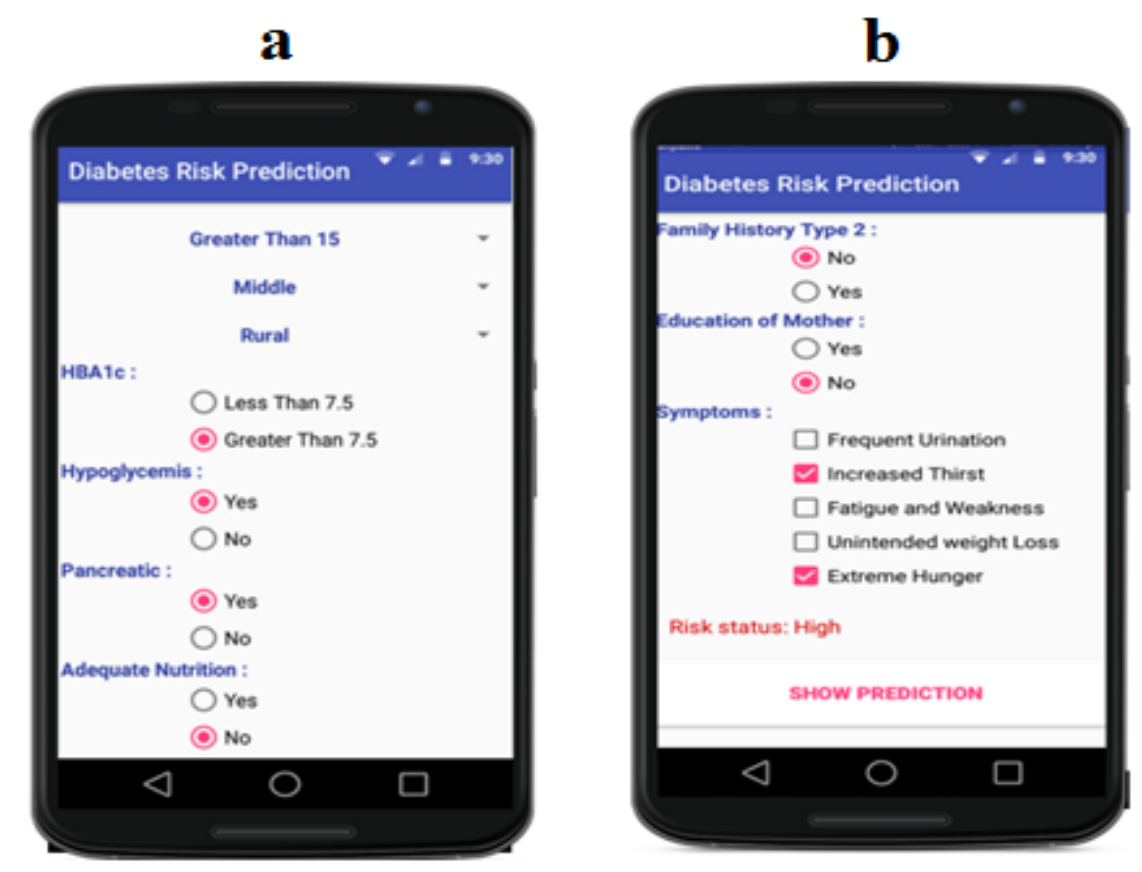

Figure 4. Smart risk prediction tool for type-1 diabetes.

Diagnosis and Prognosis by analyzing the risk factors have been made in recent research on medical science. This kind of research has drawn the attention of the new researchers. Risk analysis, risk prediction, and implementing device/tool to diagnosis the disease has been a common trend nowadays [27, 28]. In this section, the detailed result analysis has been shown. Table 1 shows the p-value and the Chi-square test of the factors. Among the factors, age has a $p$-value of $0.000<0.05$ and $\chi 2$ - Test value of 92.146. Figure 1 shows the frequency distribution with the probability of each subfactor for both case and control groups. Comparing $\chi 2$ - Test value with the other factors age is most significant. From Table 2, it can be defined that among the subfactors, "Greater than 15 " has the most probability $(0.88)$ to be affected by Type-1 Diabetes. On the other hand, other subfactors have the probability (Less than 15 is 0.42 ), (Less than 11 is 0.2 ), (Less than 5 is 0.18 ). A worldwide study showed that approximately the same number of boys and girls are affected by type- 1 diabetes, and the incidence peak of type-1 diabetes is at puberty [29]. This result is slightly different from our findings as our result has shown that the probability of affecting by type- 1 diabetes between ages 11 to 15 is 0.42 . Sex, Area of residence, Family history of both Type- 1 and Type- 2 Diabetes are some of the significant factors with $p$-value $\leq 0.05$, which indicates that the factors 
are highly significant. A family history of type-1 diabetes is one of the significant risk factors, which is quite similar to the findings of a study of Germany [30]. Type-1 Diabetes has a significant relationship with pandemic COVID-19 [31] and changing epidemiology [32-34]. So, our proposed model will also be helpful for the early detection of Type-1 Diabetes patients. It will also be highly favorable for COVID-19 patients.

\section{Conclusions}

A risk prediction tool and detailed risk factor analysis have been done in this article. Statistical analysis like p-value, Confidence Interval, Chi-square test has been done to find the risk factors. Data mining approach like ranking and probability of risk factors has also been made to find out the risk level among the factors. By analysis, a weightage value is given to each factor and subfactors by which a flow chart was designed. The flow chart or so-called decision tree may give the decision whether the person is affected and how much possibility to be affected by Type-1 Diabetes.

\section{Funding}

This research received no external funding.

\section{Acknowledgments}

The authors are grateful who have participated in this research work.

\section{Conflicts of Interest}

The authors declare no conflict of interest.

\section{References}

1. Narsale, A.; Moya, R.; Robertson, H.K.; Davies, J.D.; Type 1Diabetes TrialNet Study Group. Data on correlations between $\mathrm{T}$ cell subset frequencies and length of partial remission in type 1 diabetes. Data in brief 2016, 8, 1348-1351, https://doi.org/10.1016/j.dib.2016.07.059.

2. Domínguez, C.; Ruiz, E.; Gussinye, M.; Carrascosa, A. Oxidative stress at onset and in early stages of type 1 diabetes in children and adolescents. Diabetes care 1998, 21, 1736-1742, https://doi.org/10.2337/diacare.21.10.1736.

3. Konrad, K.; Vogel, C.; Bollow, E.; Fritsch, M.; Lange, K.; Bartus, B.; Holl, R.W.; German/Austrian DPV Initiative and the competence network of diabetes. Current practice of diabetes education in children and adolescents with type 1 diabetes in Germany and Austria: analysis based on the German/Austrian DPV database. Pediatric diabetes 2016, 17, 483-491, https://doi.org/10.1111/pedi.12330.

4. McGill, D.E.; Levitsky, L.L. Management of hypoglycemia in children and adolescents with type 1 diabetes mellitus. Current diabetes reports 2016, 16, https://doi.org/10.1007/s11892-016-0771-1.

5. Rani, S.; Gahlot, K.; Kumar, A. Experimental evidences of antidiabetic activity of aqueous extract of Cressa cretica L. on streptozotocin induced diabetes in rats. Letters in Applied NanoBioScience 2020, 9, 774-778, https://doi.org/10.33263/LIANBS91.774778.

6. Wu, Y.L.; Ding, Y.P.; Gao, J.; Tanaka, Y.; Zhang, W. Risk factors and primary prevention trials for type 1 diabetes. International journal of biological sciences 2013, 9, 666-679, https://doi.org/10.7150/ijbs.6610.

7. Eisenbarth, G.S. Type 1 diabetes mellitus. Joslin's diabetes mellitus 2005, 14, 399-424.

8. Ahmed, K.; Jesmin, T.; Fatima, U.; Moniruzzaman, M.; Emran, A.A.; Rahman, M.Z. Intelligent and effective diabetes risk prediction system using data mining. Orient J Comput Sci Technol 2012, 5, 215-221.

9. American Diabetes Association. Diagnosis and classification of diabetes mellitus. Diabetes care 2014, 37, S81-S90, https://doi.org/10.2337/dc14-S081.

10. Krischer, J.P.; Liu, X.; Lernmark, Å.; Hagopian, W.A.; Rewers, M.J.; She, J.X.; Toppari, J.; Ziegler, A.G.; Akolkar, B. The influence of type 1 diabetes genetic susceptibility regions, age, sex, and family history on the progression from multiple autoantibodies to type 1 diabetes: a TEDDY study report. Diabetes 2017, 66, 3122-3129, https://doi.org/10.2337/db17-0261. 
11. Harjutsalo, V.; Lammi, N.; Karvonen, M.; Groop, P.H. Age at onset of type 1 diabetes in parents and recurrence risk in offspring. Diabetes 2010, 59, 210-214, https://doi.org/10.2337/db09-0344.

12. Kawasaki, E.; Matsuura, N.; Eguchi, K. Type 1 diabetes in Japan. Diabetologia 2006, 49, https://doi.org/10.1007/s00125-006-0213-8.

13. Songini, M.; Mannu, C.; Targhetta, C.; Bruno, G. Type 1 diabetes in Sardinia: facts and hypotheses in the context of worldwide epidemiological data. Acta diabetologica 2017, 54, 9-17, https://doi.org/10.1007/s00592-016-0909-2.

14. Karvonen, M.; Viik-Kajander, M.; Moltchanova, E.; Libman, I.; LaPorte, R.; Tuomilehto, J. Incidence of childhood type 1 diabetes worldwide. Diabetes Mondiale (DiaMond) Project Group. Diabetes care 2000, 23, 1516-1526, https://doi.org/10.2337/diacare.23.10.1516.

15. Harjutsalo, V.; Reunanen, A.; Tuomilehto, J. Differential transmission of type 1 diabetes from diabetic fathers and mothers to their offspring. Diabetes 2006, 55, 1517-1524, https://doi.org/10.2337/db05-1296.

16. Gaur, P.K.; Pal, H.; Puri, D.; Kumar, N.; Shanmugam, S.K. Formulation and development of hesperidin loaded solid lipid nanoparticles for diabetes. Biointerface Research in Applied Chemistry 2020, 10, 47284733, https://doi.org/10.33263/BRIAC101.728733.

17. Gholamhoseinian, A.; Shahouzehi, B.; Mohammadi, G. Trace Elements Content of Some Traditional Plants Used for the Treatment of Diabetes Mellitus. Biointerface Research in Applied Chemistry 2020, 10, 61676173, https://doi.org/10.33263/BRIAC105.61676173.

18. Dziubanovskyi, I.Y.; Pidruchna, S.R.; Melnyk, N.A.; Verveha, B.M.; Hudyma, A.A.; Logoyda, L.S. Status of cellular immunity in rats under conditions of acute widespread petitonitis in the setting of diabetes mellitus. Biointerface Research in Applied Chemistry 2020, 10, 5243-5246, https://doi.org/10.33263/BRIAC102.243246.

19. Ahmed, K.; Jesmin, T. Comparative Analysis of Data Mining Classification Algorithms in Type-2 Diabetes Prediction Data Using WEKA Approach. International Journal of Science and Engineering 2014, 7, 155160, https://doi.org/10.12777/ijse.7.2.155-160.

20. Ahmed, K.; Jesmin, T.; Rahman, M.Z. Early prevention and detection of skin cancer risk using data mining. International Journal of Computer Applications 2013, 62, 1-6, https://doi.org/10.5120/10065-4662.

21. Ahmed, K.; Asaduzzaman, S.; Bashar, M.I.; Hossain, G.; Bhuiyan, T. Association assessment among risk factors and breast cancer in a low income country: Bangladesh. Asian Pac J Cancer Prev 2015, 16, 750712, http://dx.doi.org/10.7314/APJCP.2015.16.17.7507.

22. Ahmed, K.; Jahan, P.; Nadia, I.; Ahmed, F. Assessment of menopausal symptoms among early and late menopausal midlife Bangladeshi women and their impact on the quality of life. Journal of menopausal medicine 2016, 22, 39-46, https://doi.org/10.6118/jmm.2016.22.1.39.

23. Bashar, M.I.; Ahmed, K.; Uddin, M.S.; Ahmed, F.; Emran, A.A.; Chakraborty, A. Depression and Quality of Life among Postmenopausal Women in Bangladesh: A Cross-sectional Study. Journal of menopausal medicine 2017, 23, 172-181, https://doi.org/10.6118/jmm.2017.23.3.172.

24. Asaduzzaman, S.; Al Masud, F.; Bhuiyan, T.; Ahmed, K.; Paul, B.K.; Rahman, S.M. Dataset on significant risk factors for Type 1 Diabetes: A Bangladeshi perspective. Data in brief 2018, 21, 700-708, https://doi.org/10.1016/j.dib.2018.10.018.

25. Raihan, M.; Mondal, S.; More, A.; Sagor, M.O.F.; Sikder, G.; Majumder, M.A.; Al Manjur, M.A.; Ghosh, K. December. Smartphone based ischemic heart disease (heart attack) risk prediction using clinical data and data mining approaches, a prototype design. IEEE 19th International Conference on Computer and Information Technology 2019, 299-303.

26. Al Masud, F.; Royel, M.R.I.; Sajal, M.M.H.K.; Jahan, S.; Paul, B.K.; Ahmed, K. Smart Risk Prediction Tools of Appendicitis Patients: A Machine Learning Approach. Biointerface Research in Applied Chemistry 2021, 11, 7804-7813, https://doi.org/10.33263/BRIAC111.78047813.

27. Thomas, G.; Kenny, L.C.; Baker, P.N.; Tuytten, R. A novel method for interrogating receiver operating characteristic curves for assessing prognostic tests. Diagnostic and prognostic research 2017, 1, https://doi.org/10.1186/s41512-017-0017-y.

28. van Doorn, S.; Brakenhoff, T.B.; Moons, K.G.; Rutten, F.H.; Hoes, A.W.; Groenwold, R.H.; Geersing, G.J. The effects of misclassification in routine healthcare databases on the accuracy of prognostic prediction models: a case study of the CHA2DS2-VASc score in atrial fibrillation. Diagnostic and prognostic research 2017, 1, https://doi.org/10.1186/s41512-017-0018-X.

29. Soltesz, G.; Patterson, C.C.; Dahlquist, G.; EURODIAB Study Group. Worldwide childhood type 1 diabetes incidence-what can we learn from epidemiology? Pediatric diabetes 2007, 8, 6-14, https://doi.org/10.1111/j.1399-5448.2007.00280.x.

30. Bonifacio, E.; Hummel, M.; Walter, M.; Schmid, S.; Ziegler, A.G. IDDM1 and multiple family history of type 1 diabetes combine to identify neonates at high risk for type 1 diabetes. Diabetes Care 2004, 27, 26952700, https://doi.org/10.2337/diacare.27.11.2695.

31. Garg, S.K.; Rodbard, D.; Hirsch, I.B; and Forlenza, G.P. Managing new-onset type 1 diabetes during the COVID-19 pandemic: challenges and opportunities. Diabetes Technology \& Therapeutics 2020, 22, 6, 431439. Doi: $10.1089 /$ dia.2020.0161 
32. Sussman, M.; Benner, J.; Haller, M.J.; Rewers, M.; Griffiths, R. Estimated lifetime economic burden of type 1 diabetes. Diabetes Technology \& Therapeutics 2020, 22, 121-130. DOI: 10.1089/dia.2019.0398

33. Norris, J.M.; Johnson, R.K.; Stene, L.C. Type 1 diabetes - early life origins and changing epidemiology. The Lancet Diabetes \& Endocrinology 2020, 8, 226-238. https://doi.org/10.1016/S2213-8587(19)30412-7

34. Warshauer, J.T.; Bluestone, J.A.; Anderson, M.S. New frontiers in the treatment of type 1 diabetes. Cell Metabolism 2020, 31, 46-61. https://doi.org/10.1016/j.cmet.2019.11.017 